\title{
PREVALENCE OF DIAGNOSED AND UNDIAGNOSED DIABETES IN A RURAL COMMUNITY: A HOME-BASED SCREENING
}

\section{KRISHNAVENI KANDASAMY ${ }^{1}$, SHANMUGA SUNDARAM RAJAGOPAL ${ }^{2 *}$, KAMESWARAN RAMALINGAM $^{1}$, KARTHIKEYAN KRISHNAN ${ }^{1}$}

${ }^{1}$ Department of Pharmacy Practice, Faculty of Pharmacy, Pacific Academy of Higher Education and Research University, Udaipur - 313 024, Rajasthan, India. ${ }^{2}$ Department of Pharmacology, J.K.K Nattraja College of Pharmacy, Kumarapalayam - 638 183, Tamil Nadu, India. Email: malshan34@gmail.com

Received: 30 January 2018, Revised and Accepted: 30 March 2018

ABSTRACT

Objectives: Diabetes is one of the main global risks of mortality and is seen with a drastic rise in developing nations in accordance with rise in age. The main aim of the study is to find the prevalence of diabetes and pre-diabetes and its associated risk factors among the rural community based on diagnostic criteria.

Methods: This cross-sectional study was conducted in a rural community of Salem district, Tamil Nadu, India. Patient data (demographics, lifestyle factors, and medical reports) were collected with the help of a questionnaire.

Results: Of 780 populations, 425 were included for the screening of diabetes based on inclusion criteria. Of the 425 screened samples, 224 (52.7\%) were diagnosed with diabetes. From these 224 diabetic cases, 133 (31.3\%) were known cases of diabetes, 26 (6.1\%) were newly diagnosed diabetic cases, and 65 (15.3\%) were pre-diabetic cases. Most of the diabetic patients $140(62.5 \%)$ were illiterate, and 159 (71\%) were never had physical activities. A positive association $(\mathrm{p}<0.05)$ was observed between diabetes and age, body mass index (BMI) and tobacco use other than smoking. 65 patients were found to be pre-diabetes, among which $41.5 \%$ (27 cases) were male and 58.5\% (38 cases) were female. A positive association $(\mathrm{p}<0.05)$ was observed between pre-diabetes and age, family history of diabetes and HTN, BMI, and lifestyle factors such as tobacco use, alcohol consumption, and smoking.

Conclusion: Our study demonstrated that the burden of diabetes was observed to be increasing in India and it is becoming common among communities. Patient awareness and timely diagnosis and intervention may limit the progression of the disease.

Keywords: Prevalence, Pre-diabetes, Diabetes.

(C) 2018 The Authors. Published by Innovare Academic Sciences Pvt Ltd. This is an open access article under the CC BY license (http://creativecommons. org/licenses/by/4. 0/) DOI: http://dx.doi.org/10.22159/ajpcr.2018.v11i5.24906

\section{INTRODUCTION}

Diabetes is one of the main global risks for mortality and is seen with a drastic rise in developing nations in accordance with the rise in age [1]. In 2011, the Indian Council of Medical Research, India Diabetes study, has estimated that 62.4 million populations were affected with diabetes and 77.2 million with pre-diabetes, respectively. The International Diabetes Federation estimated that 40.9 million populations were affected with type 2 diabetes, and this may further rise to 69.9 million by 2025 [2]. The disease now affects more than 62 million Indians, which is more than $7.1 \%$ of Indian adult population [3]. An estimate shows that nearly 1 million Indians die due to diabetes every year. The average age of onset is 42.5 years [4]. Of all the states, Maharashtra and Tamil Nadu seem to have the highest prevalence of diabetes. Apart from the health risks, diabetes pushes the masses to poverty. News reports say that about a fourth of a person's income could be spent managing diabetes and diabetes-related health issues [5].

Diabetes screening and identification are very simple processes requiring minimal effort on the part of patients. Cities and suburban regions have a good number of screening and detection centers. Much of rural India, however, is not adequately equipped to detect diabetes early on. According to estimates, about $50 \%$ of diabetics in India, mostly in rural areas, are not aware of their condition. An estimated one million Indians die each year due to diabetes. Every adult over the age of 40 is at risk, but almost, no awareness of the disease exists in the country [5].

Population survey is the best means to detect large numbers of hitherto undiagnosed diabetics, as well as to create awareness about the disease against the masses. It is also possible to find the high-risk group using simple limits such as family history and lifestyle. The area for studying the prevalence of diabetes is an industrial area, where most of the people are illiterates and working class people. Therefore, the results of this study can easily be used to assess and evaluate the major risk factors that may lead to diabetes. Unfortunately, there is still inadequate awareness about the real dimension of the problem among the general public. Hence, an attempt has been being made to assess the prevalence and associated risk factors of diabetes in rural population.

\section{METHODS}

\section{Study site and study design}

This community-based cross-sectional study was carried out as a house-to-house based survey, for 6 months at Valayakaranur and Vattamalai, rural villages, near Kumarapalayam town, Salem district, Tamil Nadu, India. The study population was selected according to the inclusion criteria. Inclusion criteria include population between 35 and 75 years, not pregnant. Subjects for screening were selected according to the questionnaire, willing to undergo screening tests, and providing a signed consent.

\section{Assessment}

Subjects' data were collected in two steps. During the first, homebased survey; questionnaire was used to gather information on subjects' demographics, medical history, family history, and lifestyle parameters. Subjects were selected for screening based on the factors in the questionnaire and inclusion criteria. Patients without previously 
reported diabetes, with random blood sugar (RBS) $\geq 200 \mathrm{mg} / \mathrm{dl}$ or oral glucose tolerance test (OGTT) $\geq 200 \mathrm{mg} / \mathrm{dl}$, were considered as new cases with diabetes mellitus (DM) (as per the American Diabetes Association).

A pilot study was conducted within a population consisting of 50 subjects, and the RBS was used to screen in this study. Later on, due to the increased number of subject dropout, the study protocol was modified to screen fasting blood sugar (FBS) instead of RBS. A patient whose diabetes status was not known and had either RBS/OGTT levels between 140 and $<200 \mathrm{mg} / \mathrm{dl}$ or FPG levels between 100 and $<126 \mathrm{mg} / \mathrm{dl}$ was defined as pre-diabetes.

Height was measured with a tape to the nearest centimeter. Subjects were requested to stand upright without any chapels or shoes with their back against the wall, heels together, and eyes direct forward. Weight was measured using a weighing machine and was recorded to the nearest $0.5 \mathrm{~kg}$. Body mass index (BMI) was calculated using the formula: weight $(\mathrm{kg}) /$ height $\left(\mathrm{m}^{2}\right)$.

\section{Statistical analysis}

Descriptive statistics using mean (M) and standard deviation (SD) was used for analyzing continuous variables such as age and BMI, whereas percentage and frequency were used for categorical variables such as gender and disease prevalence. Chi-square test was used for the comparison or finding the significance between groups. A $p<0.05$ was considered as statistically significant. All the statistical analyses for significance were found by GraphPad prism version 6 .

\section{RESULTS}

Of the 780 total populations, 425 were selected for screening tests based on the inclusion criteria and risk factors. 224 (52.7\%) subjects of the total study population were found to have DM and 201 (47.3\%) as non-diabetes.

\section{Prevalence of diabetes}

More than half $(52.7 \%)$ of the study group was found to be diabetic (Table 1). Of the 224 reported cases, 133 (31.3\% of 425) were "known" cases of diabetics, 26 ( $6.1 \%$ of 425 ) were newly diagnosed cases, and $65(15.3 \%$ of 425$)$ were pre-diabetics. Most of the diabetic patients (140 [62.5\%]) were illiterate, while 159 (71\%) never had any sort of physical activities (Tables 2 and 3).

A comparison between those with and without diabetes is shown in Table 4. The mean age of diabetic patient was $60.2 \pm 9.3$ years and was found to be in higher age group $(52.7 \pm 11.8)$, significantly $(p<0.0001)$ than that of patients without diabetes. The diabetes status associated with the subjects $(\mathrm{p}<0.0001)$ was found to proportionally increase with increase in age, and the highest proportion of diabetics was observed in the age group of 5665 years $(35.7 \%, \mathrm{n}=80)$. We could not ascertain any significance, regarding family history, gender, and coexistence of diabetes with HTN than those without diabetes.

Tobacco (31.7\%) use, other than smoking, was found to be statistically significant $(\mathrm{p}<0.0001)$ in comparing patients with diabetes and nondiabetes.

Changes in BMI were also studied, and it showed a positive relationship with and without diabetes. The number of diabetics was found to be high in BMI $(30+[25.4 \%, 57$ cases $])$ and it showed increasing BMI $(\mathrm{p}=0.0111)$

\section{Prevalence of pre-diabetes}

Of 425 subjects, 225 subjects were screened according to the work methodology. $28.9 \%(n=65)$ of the screened subjects were found to be pre-diabetics. Among the pre-diabetic cases, the number of females was found to be more $(n=38,16.9 \%)$ than male subjects $(n=27,12 \%)$, which was also statistically insignificant.

Table 5 shows that age, family history of diabetes and HTN, BMI, and lifestyle factors such as tobacco use, alcohol consumption, and smoking showed a significant association with subjects having pre-diabetes than without pre-diabetes.

The number of pre-diabetes was found to be decreasing with the progression of age. The mean age was $50.2 \pm 8.5$ significantly younger $(p<0.0001)$ than that of subjects without pre-diabetes (58.8 \pm 11.5 years). The age distribution, with the highest proportion of pre-diabetes, was observed in $46-55$ age group $(47.7 \%, \mathrm{n}=31)$.

BMI of 25-29.9 in overweight subjects showed more a number of prediabetes than without pre-diabetes. This was statistically significant $(p<0.0001)$ when compared with and without pre-diabetic subjects. An increase in BMI was found to be associated with increases in the number of pre-diabetes which may, later on, manifest as diabetes. The prevalence of diabetic subjects was found to be more in the obese class, and hence, our study showed a positive relation to pre-diabetes and diabetes with BMI.

Although family history of diabetes and HTN showed no significant association with diabetes in the study population, it was found to be significant in pre-diabetic subjects $(p=0.0491$ and $p=0.0303$, respectively). Of 65 pre-diabetic subjects, 10 had a family history of diabetes and 7 had a family history of HTN. Lifestyle factors such as alcohol consumption, smoking, tobacco chewing was found to be significant in pre-diabetes than without prediabetes $(\mathrm{p}=0.0073$, $\mathrm{p}=0.0224, \mathrm{p}=0.0001$ respectively) [Table 5].

Table 1: Overall prevalence of diabetes

\begin{tabular}{llll}
\hline Category & Total number of subjects $(\mathbf{n = 4 2 5 )}(\mathbf{\% )}$ & Number of male (\%) & Number of female (\%) \\
\hline Overall diabetes & $224(52.7)$ & $111(26.1)$ & $113(26.6)$ \\
Known & $133(31.3)$ & $72(16.9)$ & $61(14.4)$ \\
Newly diagnosed & $26(6.1)$ & $12(2.8)$ & $14(3.3)$ \\
Pre-diabetes & $65(15.3)$ & $27(6.4)$ & $38(8.9)$ \\
Non-diabetes & $201(47.3)$ & $105(24.7)$ & $96(22.6)$ \\
\hline
\end{tabular}

Table 2: Prevalence of diabetes based on educational status

\begin{tabular}{lllll}
\hline Education level & $\begin{array}{l}\text { Pre-diabetes } \\
(\mathbf{n = 6 5 )}(\mathbf{\% )}\end{array}$ & $\begin{array}{l}\text { Newly diagnosed } \\
(\mathbf{n = 2 6 )} \mathbf{( \% )}\end{array}$ & $\begin{array}{l}\text { Known diabetes } \\
(\mathbf{n = 1 3 3 ) ( \% )}\end{array}$ & $\begin{array}{l}\text { Non-diabetes } \\
(\mathbf{n = 2 0 1}) \mathbf{( \% )}\end{array}$ \\
\hline No education & $52(80.0)$ & $19(73)$ & $72(54.1)$ & $108(53.7)$ \\
Lower education & $10(15.4)$ & $7(27)$ & $48(36.1)$ & $56(27.9)$ \\
Upper secondary & $2(3.1)$ & - & $7(5.3)$ & $18(8.9)$ \\
First stage of tertiary education & $1(1.5)$ & - & $6(4.5)$ & $11(5.5)$ \\
Second stage of tertiary education & - & - & $8(4.0)$ \\
\hline
\end{tabular}


Table 3: The prevalence of diabetes based on physical exercise

\begin{tabular}{|c|c|c|c|c|}
\hline Physical activity (Exercise) & $\begin{array}{l}\text { Pre-diabetes } \\
(n=65)(\%)\end{array}$ & $\begin{array}{l}\text { Newly diagnosed } \\
(n=26)(\%)\end{array}$ & $\begin{array}{l}\text { Known } \\
(n=133)(\%)\end{array}$ & $\begin{array}{l}\text { Non-diabetes } \\
(n=201)(\%)\end{array}$ \\
\hline No physical activities & $43(66.1)$ & $18(69.2)$ & 98 (73.7) & $118(58.7)$ \\
\hline Mild & $14(21.5)$ & $7(31.8)$ & $19(14.3)$ & $51(25.4)$ \\
\hline Moderate & $8(12.3)$ & $1(4.5)$ & $16(12.0)$ & $29(14.4)$ \\
\hline Regular physical activity & - & - & - & $3(1.5)$ \\
\hline
\end{tabular}

Table 4: Comparison between subjects with and without diabetes

\begin{tabular}{|c|c|c|c|}
\hline Variables & With diabetes $(n=224)(\%)$ & Without diabetes $(n=201)(\%)$ & $\mathbf{p}$ \\
\hline \multicolumn{4}{|l|}{ Sex n $(\%)$} \\
\hline Male & $111(49.5)$ & $105(52.2)$ & \multirow{2}{*}{0.5804} \\
\hline Female & $113(50.4)$ & $96(47.8)$ & \\
\hline \multicolumn{4}{|l|}{ Age categories n (\%) } \\
\hline $35-45$ & $15(6.7)$ & $75(37.3)$ & \multirow[t]{3}{*}{$<0.0001^{* *}$} \\
\hline $46-55$ & $58(25.9)$ & $49(24.4)$ & \\
\hline $56-65$ & $80(35.7)$ & $38(18.9)$ & \\
\hline Mean \pm SD & $60.2 \pm 9.3$ & $52.7 \pm 11.8$ & $<0.0001^{* *}$ \\
\hline \multicolumn{4}{|l|}{ Coexistence of HTN n (\%) } \\
\hline Yes & $69(30.8)$ & $74(36.8)$ & 0.3566 \\
\hline \multicolumn{4}{|l|}{ Family history n (\%) } \\
\hline Diabetes & $38(16.9)$ & $45(22.4)$ & 0.2484 \\
\hline HTN & $42(18.7)$ & $48(23.9)$ & 0.2976 \\
\hline \multicolumn{4}{|l|}{ BMI n (\%) } \\
\hline$<18.5 / \mathrm{m} 2$ & $50(22.3)$ & $31(15.4)$ & \multirow[t]{4}{*}{$0.0111^{*}$} \\
\hline $23-24.9$ & $43(19.2)$ & $42(20.9)$ & \\
\hline $25-29.9$ & $49(21.9)$ & $47(23.4)$ & \\
\hline $30+$ & $57(25.4)$ & $36(17.9)$ & \\
\hline \multicolumn{4}{|l|}{ Lifestyle factors n (\%) } \\
\hline Smoking past and present & $73(32.6)$ & $61(30.3)$ & 0.7201 \\
\hline Alcohol consumption (past and present) & $77(34.4)$ & $74(36.8)$ & 0.7174 \\
\hline Other tobacco use & $71(31.7)$ & $154(76.6)$ & $<0.0001^{* *}$ \\
\hline
\end{tabular}

*and** indicates the significance at the level ( $\mathrm{p}<0.05$ and $\mathrm{p}<0.01)$. SD: Standard deviation, BMI: Body mass index

Table 5: Comparison between subjects with and without pre-diabetes

\begin{tabular}{|c|c|c|c|}
\hline Variables & With pre-diabetes $(n=65)(\%)$ & Without pre-diabetes $(n=160)(\%)$ & p value \\
\hline \multicolumn{4}{|l|}{ Sex n (\%) } \\
\hline Male & $27(41.5)$ & $74(46.2)$ & \multirow{2}{*}{0.5196} \\
\hline Female & $38(58.5)$ & $86(53.8)$ & \\
\hline \multicolumn{4}{|l|}{ Age categories n (\%) (year) } \\
\hline $35-45$ & $20(30.8)$ & $32(20)$ & \multirow[t]{4}{*}{$<0.0001^{* *}$} \\
\hline $46-55$ & $31(47.7)$ & $24(15)$ & \\
\hline $56-65$ & $11(16.9)$ & $48(30)$ & \\
\hline $66-75$ & $3(4.6 \%)$ & $56(35 \%)$ & \\
\hline Mean \pm SD & $50.2 \pm 8.5$ & $58.8 \pm 11.5$ & $<0.0001^{* *}$ \\
\hline \multicolumn{4}{|l|}{ Coexistence of HTN n (\%) } \\
\hline Yes & $16(24.6 \%)$ & $52(32.5 \%)$ & 0.3865 \\
\hline \multicolumn{4}{|l|}{ Family history n (\%) } \\
\hline Diabetes & $10(15.4 \%)$ & $51(31.9 \%)$ & $0.0491 *$ \\
\hline HTN & $7(10.8 \%)$ & $43(26.9 \%)$ & $0.0303^{*}$ \\
\hline \multicolumn{4}{|l|}{ BMI n (\%) } \\
\hline$<18.5 / \mathrm{m} 2$ & $4(6.1 \%)$ & $37(23.1 \%)$ & \multirow[t]{5}{*}{$<0.0001^{* *}$} \\
\hline $18.5-22.9$ & $6(9.2 \%)$ & $35(21.9 \%)$ & \\
\hline $23-24.9$ & $17(26.1 \%)$ & $28(17.5 \%)$ & \\
\hline $25-29.9$ & $28(43.1 \%)$ & $22(13.7 \%)$ & \\
\hline $30+$ & $10(15.4 \%)$ & $38(23.7 \%)$ & \\
\hline \multicolumn{4}{|l|}{ Lifestyle factors n (\%) } \\
\hline Smoking past and present & $33(50.8 \%)$ & $141(88.1 \%)$ & $0.0224^{*}$ \\
\hline Alcohol consumption (past and present) & $31(47.7 \%)$ & $147(91.8 \%)$ & $0.0073^{*}$ \\
\hline Other tobacco use & $14(21.5 \%)$ & $140(87.5 \%)$ & $<0.0001^{* *}$ \\
\hline
\end{tabular}

\section{DISCUSSION}

This study was conducted to identify the prevalence of diabetes in the selected community and to find the significance of various risk factors that are associated with the disease. The study conducted was also helpful in finding the significance of an early diagnosis of the disease state. The overall prevalence of diabetes showed that women were more to have diabetes. This may be due to the fact that increased BMI, physical inactivity, hormonal imbalance and pre-diabetes were found to be higher in females than males [6]. 
As per the World Health Organization (WHO) 2015 data, India had 69.2 million people living with DM (8.7\%), of these; it remained undiagnosed in more than 36 million people [7]. Recent years have witnessed a rapid rise in the prevalence of diabetes in India. This could be attributed to the increasing levels of sedentarism, urbanization, and consumption of energy-dense and fiber/micronutrient-poor food [2]

In the present study, subjects with no formal education were found to have a higher prevalence of diabetes compared with the educated group, which is in agreement with previous studies [8]. Imparting knowledge about diabetes to the community is the first step in prevention and early detection of the disease and prevention of its complications [9].

In our study, physical activity among the community is very low. Sedentarism may also contribute to increase the prevalence of diabetes [10]. Insulin sensitivity improves in obese individuals who accomplish a significant increase in maximal oxygen consumption during physical training, even when only minor changes in body weight and fat composition occur [11]. Kokiwar et al. reported that reduced physical activity was an important predictor of diabetes [12]

In our study, pre-diabetes and newly diagnosed diabetes reporting an age group between 46 and 55 years were higher, whereas already known diabetes was higher in the age group of 56-65 years. This may be due to the fact that age probably represents accumulation of environmental influences and the effect of genetically programmed senescence in the body systems $[13,14]$. Risk factor management can decrease progression of pre-diabetes to diabetes so that diabetes can be prevented or delayed $[15,16]$.

Diabetes reporting with BMI between 25 and $29.9 \mathrm{~m} 2$ is higher followed by $30+$. Similar finding was reported by Liberty and Kodim Arafat et al. $[17,18]$. The WHO study group has stated that obesity reduces the number of insulin receptors on target cells, but in most cases, it produces insulin resistance through post-receptor changes [19]. Alcohol was found to be negatively associated with DM in this study. An association between alcohol and DM has been documented by Gibbons et al. [20]. Levitt et al., on the other hand, reported that alcohol intake was not a significant risk factor for DM in South Africa [21]. However, it shows positive relations with pre-diabetes in the study population. A study by Bukelo et al., showed that several risk factors such as family history, physical inactivity, smoking and alcohol consumption were found among the community which was similar to our findings [22]. An illiterate person living in sedentary lifestyle is at most risk [23]. Patient knowledge and awareness of target FBG levels play important roles in the ability to successfully self-monitor DM [24]

This study had limitations also. One of the main limitations of this study was the inclusion of small population from a rural area, and these results can be varied in urban areas. The relation of BMI with diabetes is studied here. However, calculating the waistline circumference is more advised than BMI. Despite these limitations, this study was helpful in finding the various problems of the community and its relation to diabetes and pre-diabetes.

\section{CONCLUSION}

This study helps in the early detection of diabetes and pre-diabetes among the populations in the pre-clinical stages and offers them an opportunity to modify long-term risk before serious complications occur. Patient awareness and timely diagnosis and intervention may possibly limit the progression of the disease.

\section{CONFLICTS OF INTEREST}

Authors declare no conflict of interest.

\section{AUTHORS' CONTRIBUTION}

KK contributed in study design, data collection, and manuscript writing, SSR contributed in study design, final review, and approval, and KR and KK contributed in statistical data analysis.

\section{REFERENCES}

1. World Health Organization: Global Health Risks: Mortality and Burden of Diseases Attributable to Selected Major Risks. Published December 11, 2010. Available from: http://www.who.int/healthinfo/global burden disease/GlobalHealthRisks_report_full.pdf. [Last accessed on $201 \overline{6}$ Jun 18].

2. Joshi SR, Saboo B, Vadivale $\bar{M}$, Dani SI, Mithal A, Kaul U, et al. Prevalence of diagnosed and undiagnosed diabetes and hypertension in India - results from the screening India's twin epidemic (SITE) study. Diabetes Technol Ther 2012;14:8-15.

3. Diabetes can be Controlled in 80 Percent of Cases in India. IANS. Published February 6, 2014. Available from: https://www.news. biharprabha.com/2014/02/diabetes-can-be-controlled-in-80-percentof-cases-in-india/. [Last accessed on 2016 Apr 08].

4. Gale J. India's Diabetes Epidemic Cuts Down Millions Who Escape Poverty. Bloomberg. Published November 8, 2010. Available from: http:// www.fullertreacymoney.com/general/india-s-diabetes-epidemic-cutsdown-millions-who-escape-poverty-1691/. [Last accessed on 2015 Jun 14].

5. Patel V, Chatterji S, Chisholm D, Ebrahim S, Gopalakrishna G, Mathers $\mathrm{C}$, et al. Chronic diseases and injuries in India. Lancet 2011;377:413- 28.

6. Viswanathan M, Snehalatha C, Viswanathan V, Vidhyavathi P, Indu J, Ramachandran A. Reduction in body weight helps to delay the onset of diabetes even in non-obese with strong family history of the disease. Diab Res Clin Pract 1997;35:107-12.

7. World Health Organization. Global Report on Diabetes. Geneva: WHO; 2016

8. Caliskan D, Ozdemir O, Ocaktan E, Idil A. Evaluation of awareness of diabetes mellitus and associated factors in four health center areas. Patient Educ Couns 2006;62:142-7

9. Deshpande AD, Harris-Hayes M, Schootman M. Epidemiology of diabetes and diabetes-related complications. Phys Ther 2008;88:1254- 64 .

10. Misra A, Khurana L. Salt intake and hypertension: Walking the tight rope. J Assoc Phys India 2007;55:401-3.

11. Bjorntorp P, De Jounge K, Sjostrom L, Sullivan L. The effect of physical training on insulin production in obesity. Metabolism 1970;19:631-8.

12. Kokiwar PR, Gupta SS. Prevalence of hypertension in a rural community of central India. Int J Biol Med Res 2011;2:950-3.

13. Shantirani CS, Pradeepa R, Deepa R, Premalatha G, Saroja R, Mohan V. Prevalence and risk factors of hypertension in a south Indian population-the Chennai urban population study. J Assoc Phys India 2003;51:20-7

14. Vashitha A, Agarwal BK, Gupta S. Hospital based study: Prevalence and predictors of Type 2 diabetes mellitus in rur al population of Haryana. Asian Pac J Trop Dis 2012;2:173-9.

15. Buchanan TA. (How) can we prevent Type 2 diabetes? Diabetes 2007:56:1502-7.

16. Keech S, Colquehoun D, Best J, Kirby A, Simes RJ, Hunt D, et al. Secondary prevention of cardiovascular events with long-term pravastatin in patients with diabetes or impaired fasting glucose: Results from the LIPID trial. Diabetes Care 2003;26:2713-21.

17. Liberty IA, Kodim N. Assess pre-diabetes risk, as a golden period for prevention of diabetes. Asian J Pharm Clin Res 2017;10:349-53.

18. Arafat M, Salam A, Arafat O. The association of Type 2 diabetes with obesity and other factors: In multinational community. Int J Pharm Pharm Sci 2014;6:257-60.

19. Guideline Principles for Diabetes Care. Published April 16, 2009. Available from: http://www.ndep.nih.gov/media/guidprin_hc_eng.pdf. [Last accessed on 2014 Apr 23].

20. Gibbons LW, Wei M, Kampert JB, Mitchell TL, Blair SN. Alcohol intake and incidence of Type 2 diabetes in men. Diabetes Care 2000;23:18-22.

21. Levitt NS, Katzenellenbogen JM, Bradshaw D, Hoffman MN, Bonnici F. The prevalence and identification of risk factors for NIDDM in urban Africans in Cape Town, South Africa. Diabetes Care 1993;16:601-7.

22. Bukelo MF, Kiran D, Goud R, Bukelo MJ, Kiran BR, Kulkarni V, et al. Risk factors for non-communicable diseases among rural adolescents: A schoolbased cross-sectional study. Asian J Pharm Clin Res 2015;8:284-7.

23. Jhawat V, Gupta S, Agarwal BK, Roy P, Saini V. Prevalence of risk factors of essential hypertension and new onset of diabetes in essential hypertension in rural population of Haryana. Int J Pharm Pharm Sci 2018;10:142-8.

24. Maja L, Masia T, Binyane K, Ramathebane M. Assessment of patient counselling in diabetic and hypertensive patients in terms of patients knowledge about their medication, disease state, and lifestyle modification by pharmacy personnel at LDF clinic in Maseru. Int J Pharm Pharm Sci 2018;10:155-61. 